\title{
Costs of Treatment, Follow-Up, and Complications of Chronic Hepatitis B and Hepatitis C Infections
}

\author{
Fatma Banu Karahasanoğlư1, Ali Asan², Suzan Sacar ${ }^{1}$, Hüseyin Turgut ${ }^{1}$ \\ ${ }^{1}$ Department of Infectious Diseases and Clinical Microbiology, Pamukkale University Faculty of Medicine, Denizli, Turkey \\ ${ }^{2}$ Denizli Health Services Vocational College, Denizli, Turkey
}

\begin{abstract}
Background: Few studies have addressed the indirect costs of chronic hepatitis B and C, and none has assessed the real costs of these conditions, including indirect costs caused by loss of work, in Turkey. Aims: This study therefore analysed the costs of treatment, follow-up, and complications of chronic hepatitis $B$ and hepatitis $C$ infections to the community.

Study design: Cross-sectional study.

Methods: This study analysed patients with chronic hepatitis B and hepatitis C treated at Pamukkale University Hospital Infectious Diseases and Clinical Microbiology Clinic, Denizli, Turkey between June 2009 and June 2010. Costs of antiviral treatment and follow-up were calculated from patients' medical records, and indirect costs were analysed from questionnaires completed by patients.

Results: Data were analysed for 284 patients with chronic viral hepatitis. Indirect, hospital, treatment and total expenses were significantly higher for patients with chronic hepatitis B than for inactive hepatitis B virus carriers and patients with chronic hepatitis C. Hospital and total expenses of patients with complications were significantly higher than for patients with chronic hepatitis C. Hospital and total expenses were significantly higher for patients with than for individuals without cirrhosis. Indirect, hospital, treatment and total costs of patients were significantly higher for patients receiving combination therapy than monotherapy.
\end{abstract}

Conclusion: Reducing the costs to society of chronic hepatitis requires the development of protection and screening programs.

Key Words: Cost, chronic hepatitis B, chronic hepatitis C

Received: 23.11.2012 Accepted: 08.05.2013 Available Online Date: 27.09.2013

\section{Introduction}

The development over the last 10 years of new agents to treat chronic hepatitis $B$ and chronic hepatitis $C$ infections has led to evaluations of the costs and efficacies of these drugs (1).

Although information is available about the prevalence of Hepatitis B virus (HBV), risks related to infection and the natural history of the disease, less is known about the costs related to this disease and to healthcare services. Greater knowledge of costs can lead to the correct use of treatment agents, determination of priorities and arrangement of future healthcare policies (2). Similarly, hepatitis $C$ remains an important healthcare problem, especially since the current treatment modalities are not effective in many patients. The relatively low efficacy and high costs of interferon-alpha therapy has led to determination of the cost-effectiveness of drugs used to treat chronic hepatitis C (3). Few studies, however, have assessed indirect costs, including costs caused by loss of work. Moreover, no studies to date have analysed the actual costs, including indirect costs, of hepatitis in our country. We have therefore analysed the costs of treatment, follow-up, and complications of chronic hepatitis $B$ and hepatitis $C$ infections to the community.

\section{Materials and Methods}

This cross-sectional study involved patients with chronic hepatitis B and hepatitis C treated at Pamukkale University Hospital Infectious Diseases and Clinical Microbiology Clinic between June 30, 2009, and June 30, 2010. The study was approved by the local Medical Ethics Committee.

\section{Statistical analysis}

Data obtained from participants were analysed using the Statistical Package for the Social Sciences (SPSS) for Windows, version 10.5 .

Descriptive statistics were reported as mean \pm standard deviation, median, interquartile range, minimum and maximum values. As the distribution among the groups was not compatible with normal ranges, non-parametric tests were used. The Mann-Whitney U Test was used to calculate the association between costs and independent variables such as gender. The Kruskal-Wallis variance test was used to compare three or more independent variables such as marital and educational status. Because the age groups were found to be compatible with a normal distribution one-way ANOVA was used to evaluate the association between age groups and cost. The Chisquare test was used to determine the association between 
primary disease and age groups or gender. A $p$ value $<0.05$ was considered statistically significant.

Follow-up and antiviral treatment costs were calculated from medical records, with costs determined by analysing payments from the Social Security Foundation. To assess indirect costs, questionnaires were submitted to patients, and the statements by patients about the loss of productivity, transportation, shelter and nutrition costs during hospital visits were used to calculate indirect costs (2). Indirect costs were paid by the patients themselves.

\section{Sample election and application}

Analysis of medical records identified a total of 525 patients with chronic hepatitis $B$ and chronic hepatitis $C$ who were admitted at least once to our polyclinic. However, during the study period, only 284 of these patients were followed-up; these 284 patients agreed to participate and were included.

Direct costs included polyclinic costs, total hospital costs, follow-up costs and treatment costs, except for the costs of antiviral drugs in hospitalised patients, and doctor visits. The costs of antiviral treatment consisted only of the costs of the drugs themselves. Treatment and follow-up decisions were based on current guidelines, including those of the European Association for the Study of the Liver (EASL)-2009, the American Association for the Study of Liver Diseases (AASLD)-2009, and the Asian Pacific Association for the Study of the Liver (APASL)-2008 (4-6).

Indirect costs included patients' travel costs, loss of work during follow-up and treatment, and shelter and nutrition charges during the hospital visit. Questionnaire forms were submitted to patients face to face and one by one by a single examiner.

Patients aged $\geq 18$ years and the parents of the 2 patients aged $<18$ years were informed about the study and provided written informed consent.

\section{Results}

The 284 patients comprised 232 individuals infected with $\mathrm{HBV}, 50$ infected with Hepatitis $\mathrm{C}$ virus (HCV), 1 infected with $\mathrm{HBV}$ and $\mathrm{HCV}$, and 1 infected with $1 \mathrm{HBV}$ and Hepatitis D virus (HDV). The 284 patients consisted of 159 (56\%) males and 125 (44\%) females, of mean \pm SD age $43.49 \pm 13.07$ years (range 1675 years). We found that 40 (25.3\%) inactive HBV carriers were under 30 years old, all patients with cirrhosis were over 40 years old, and 16 (39\%) of the patients with chronic hepatitis $C$ were aged $40-49$ years.

Occupationally, 73 patients were workers (25.7\%), 68 were housewives (23.9\%), 41 were retired $(14.4 \%), 36$ were officer workers $(12.7 \%), 24$ were farmers $(8.5 \%), 14$ were students (4.9\%), and 7 were unemployed (2.5\%).

There were no statistically significantly differences in indirect, hospital, treatment and total costs in patients with chronic hepatitis $B$ and chronic hepatitis $C$ cases by sex and marital status ( $p>0.05)$. When patients' educational status was evaluated, we found that hospital and total costs were significantly higher for primary school and university graduates than for secondary school graduates $(p<0.05)$ and that indirect costs were higher for primary school than high school graduates. In addition, hospital and total costs were significantly higher for university than for high school graduates $(p<0.05)$.

When costs were evaluated according to jobs, we found that indirect costs for farmers were significantly higher than for housewives, retired persons, students and workers $(p<0.05)$. Hospital, treatment, and total costs, however, did not differ significantly by occupation ( $p>0.05)$.

Prior to the study period, 35 of the 284 (12.3\%) patients had received antiviral treatment for chronic hepatitis $B$ or chronic hepatitis $C$. Their indirect, hospital, treatment and total costs did not differ from those of patients who did not receive antiviral therapy ( $p>0.05)$.

According to guidelines, liver biopsies were taken from 14 patients. Some patients underwent upper abdominal ultrasonography (USG) once or twice per year, 12 patients underwent upper abdominal MRI, and 7 underwent dynamic upper abdominal computerised tomography (CT).

Of the 284 patients, $93(37.2 \%)$ received antiviral treatment, including 73 who received therapy for the first time or underwent treatment modification during the study period. The most frequent antiviral drug was entecavir $(n=29 ; 31.18 \%)$ followed by tenofovir ( $n=14 ; 15.05 \%)$.

Of the 50 patients with chronic hepatitis C, 22 received antiviral treatment during the study period, including 5 who received pegylated interferon-alpha 2 a monotherapy because of haemodialysis, and 17 who received pegylated interferonalpha plus ribavirin. Of the 28 untreated chronic hepatitis $C$ patients, 27 had been treated before the study period; of these, 25 achieved a sustained viral response and were followed-up for relapse and/or hepatocellular carcinoma (HCC), and both were refractory to antiviral therapy and were followed for complications such as cirrhosis and/or HCC. One patient was being prepared for antiviral treatment during the study period.

During the study period, 8 patients with possible cirrhosis were further investigated. At the beginning of the study period, 10 patients had cirrhosis. During the study period, one patient with relapsed $\mathrm{HCV}$, one with treatment refractory $\mathrm{HCV}$ and one with chronic hepatitis $\mathrm{C}$ were diagnosed with cirrhosis.

Four patients were analysed for antiviral resistance. One was resistant to entecavir and switched to tenofovir, one was resistant to adefovir and switched to entecavir treatment, and one patient treated with tenofovir was switched to entecavir because of osteoporosis.

All patients with cirrhosis, those with chronic hepatitis $C$ who were refractory to treatment, those with relapsed chronic $\mathrm{HBV}$ and chronic HCV, and those co-infected with HBV-HCV and HBV-HDV were grouped as patients with complications. The indirect, hospital, treatment and total costs of patients with chronic hepatitis B were significantly higher than those of inactive hepatitis $B$ carriers and patients with chronic hepatitis $C(p<0.05)$. The hospital and total costs of patients with complications were significantly higher than those of inactive HBV carriers and patients with chronic hepatitis $C(p<0.05)$, and the indirect and treatment costs of patients with complications were significantly higher than those of inactive HBV carriers $(p<0.05$; Table 1$)$. 
Table 1. Evaluation of costs according to primary disease

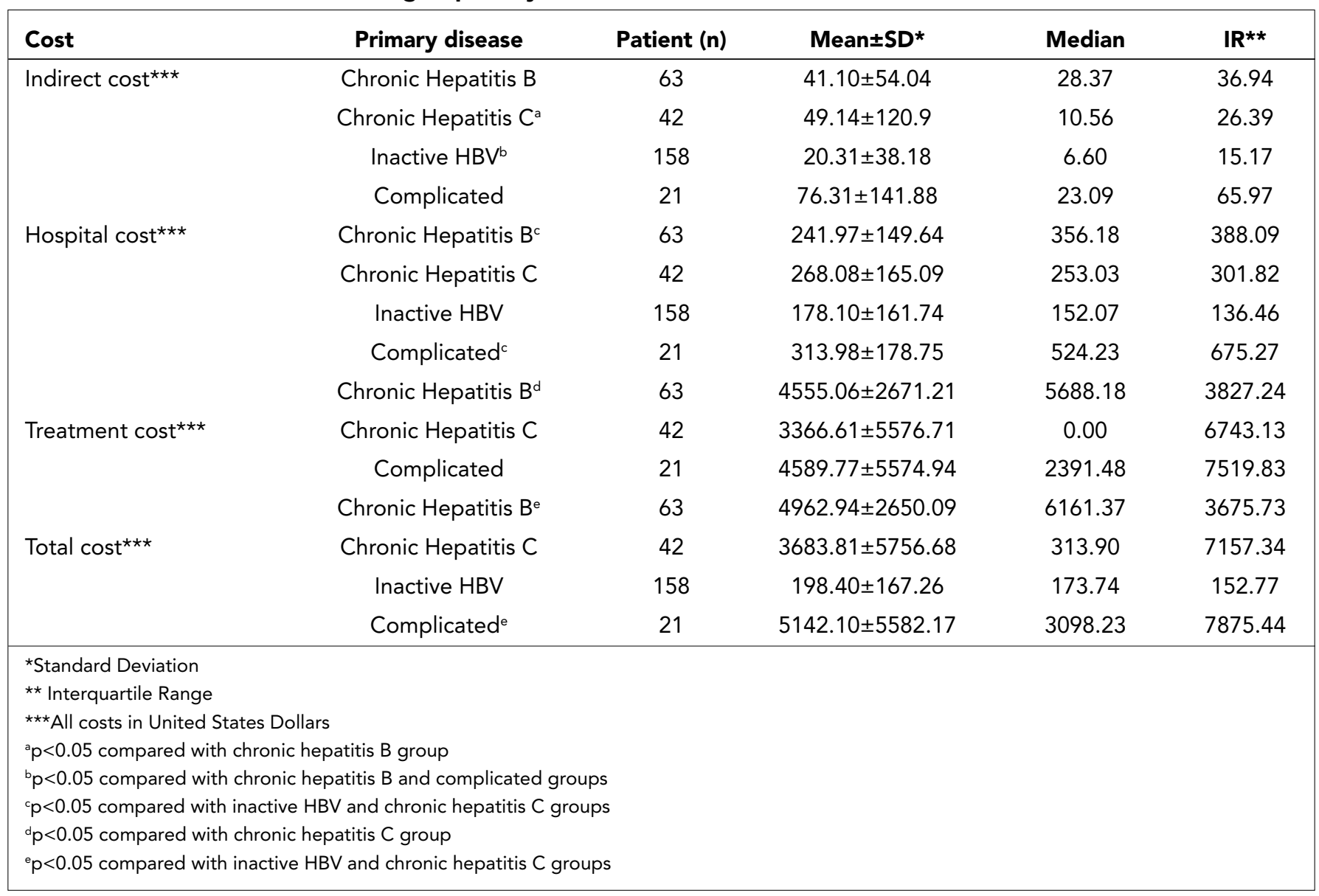

The treatment and total costs of patients treated with entecavir were significantly higher than those of patients treated with tenofovir or lamivudine, or those followed without treatment $(p<0.05)$. In addition, the hospital costs of patients treated with entecavir were significantly higher than those of patients treated with lamivudine $(p<0.05)$. The treatment and total costs of patients treated with adefovir were significantly higher than those of patients treated with lamivudine, tenofovir or entecavir $(p<0.05)$. The hospital, treatment and total costs of patients treated with tenofovir were significantly higher than those of patients treated with lamivudine $(p<0.05)$.

The treatment and total costs of patients treated with 180 $\mu \mathrm{g}$ pegylated interferon alpha-2a were significantly higher than those of patients treated with lamivudine, entecavir or tenofovir $(p<0.05)$, and the indirect, hospital, treatment and total costs of patients treated with $180 \mu \mathrm{g}$ pegylated interferon alpha-2a were significantly higher than those of patients who did not receive any antiviral therapy $(p<0.05)$.

The treatment and total costs of patients treated with 135 $\mu \mathrm{g}$ pegylated interferon alpha-2a were significantly higher than those of patients treated with lamivudine $(p<0.05)$. The treatment and total costs of patients treated with pegylated interferon alpha-2b were significantly higher than those of patients treated with lamivudine or tenofovir $(p<0.05$; Table 2).

The indirect, hospital, treatment and total costs of patients treated with pegylated interferon-alpha plus ribavirin were significantly higher than those of all other patients $(p<0.05$; Table 3). The hospital and total costs of patients with cirrhosis were significantly higher than those of patients without cirrhosis $(p<0.05 ;$ Table 4).

\section{Discussion}

HBV genotype D is the predominant HBV genotype in Turkey; this genotype is resistant to treatment, resulting in relapses, a low response to therapy and high follow-up costs (7-9). It is impossible to totally eradicate infections in all patients with chronic hepatitis B and chronic hepatitis C. Patients sustain material, physical and spiritual losses for many years. Having to obtain antiviral drugs from the other countries negatively affects the Turkish economy.

Two types of measurements are used to evaluate the cost-effectiveness of medical treatment: economic and clinical measures (10). Most cost-effectiveness analyses of chronic hepatitis utilise Markov models, as complications of chronic hepatitis develop over several decades. These models are used to evaluate quality of life time adjusted costs, including those due to premature death, and these models are also used to compare new treatments with current treatments (11). Markov models have factors that can cause bias, leading to incorrect findings in cost-effectiveness studies (12). 
Table 2. Evaluation of costs according to treatment

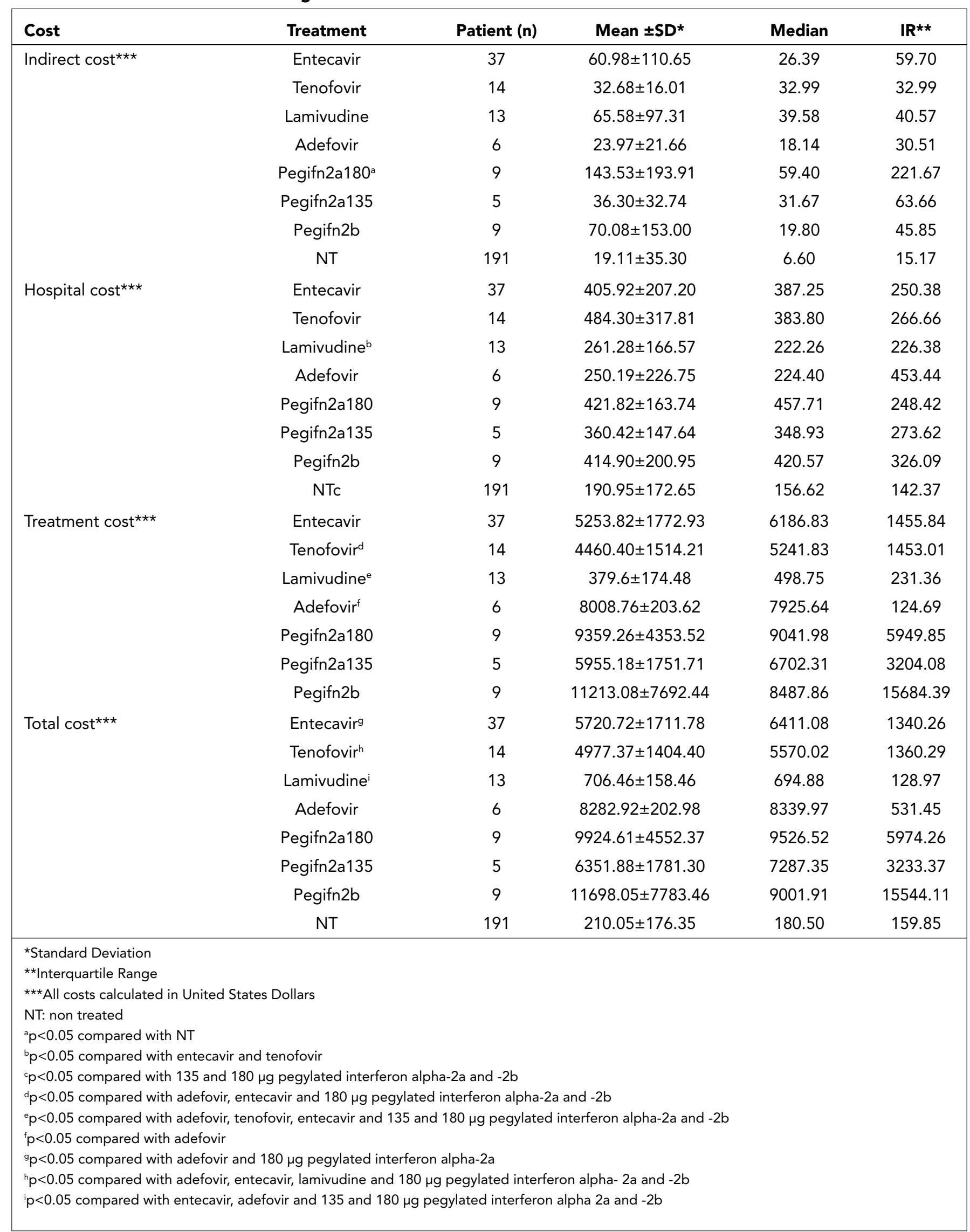


Table 3. Evaluation of the costs according to need for additional therapy

\begin{tabular}{|c|c|c|c|c|c|c|}
\hline Costs & Additional therapy & Patients (n) & Mean $\pm S D^{*}$ & Median & $\mathbf{I R}$ ** & $\mathbf{P}$ \\
\hline \multirow[t]{2}{*}{ Indirect cost ${ }^{\star \star \star}$} & No & 267 & $28.87 \pm 57.91$ & 10.56 & 26.39 & 0.037 \\
\hline & Yes & 17 & $103.19 \pm 178.76$ & 20.45 & 62.67 & \\
\hline \multirow[t]{2}{*}{ Hospital cost ${ }^{\star \star \star}$} & No & 267 & $246.17 \pm 209.36$ & 211.51 & 226.94 & 0.002 \\
\hline & Yes & 17 & $398.54 \pm 194.68$ & 429.94 & 343.85 & \\
\hline \multirow[t]{2}{*}{ Treatment cost ${ }^{\star \star \star}$} & No & 267 & $1307.38 \pm 2492.45$ & 0.000 & 498.75 & 0.0001 \\
\hline & Yes & 17 & $10334.15 \pm 6326.05$ & 8487.86 & 8700.68 & \\
\hline \multirow[t]{2}{*}{ Total cost ${ }^{\star \star \star}$} & No & 267 & $1582.42 \pm 2582.57$ & 259.86 & 641.18 & $<0.0001$ \\
\hline & Yes & 17 & $10835.88 \pm 6452.30$ & 9001.91 & 9087.55 & \\
\hline \multicolumn{7}{|l|}{ *Standard Deviation } \\
\hline
\end{tabular}

Table 4. Evaluation of the costs in patients with and without cirrhosis

\begin{tabular}{|c|c|c|c|c|c|c|}
\hline Cost & Cirrhosis & Patients ( $n$ ) & Mean $\pm S D^{*}$ & Median & $\mathbf{I R}$ ** & $\mathbf{P}$ \\
\hline \multirow[t]{2}{*}{ Indirect cost ${ }^{\star \star \star}$} & No & 271 & $30.08 \pm 62.41$ & 11.22 & 25.73 & 0.316 \\
\hline & Cirrhosis & 13 & $100.79 \pm 177.48$ & 20.45 & 169.88 & \\
\hline \multirow[t]{2}{*}{ Hospital cost ${ }^{\star \star \star}$} & No & 271 & $243.77 \pm 200.28$ & 211.51 & 227.00 & 0.001 \\
\hline & Cirrhosis & 13 & $495.27 \pm 291.83$ & 524.23 & 376.35 & \\
\hline \multirow[t]{2}{*}{ Treatment cost ${ }^{\star \star \star}$} & No & 271 & $1816.40 \pm 3593.07$ & 0.000 & 2359.60 & 0.058 \\
\hline & Cirrhosis & 13 & $2500.50 \pm 2937.17$ & 2300.13 & 4715.29 & \\
\hline \multirow[t]{2}{*}{ Total cost ${ }^{\star \star \star}$} & No & 271 & $2090.26 \pm 3693.50$ & 267.87 & 2780.23 & 0.008 \\
\hline & Cirrhosis & 13 & $3096.55 \pm 3067.14$ & 2976.29 & 4667.79 & \\
\hline $\begin{array}{l}{ }^{*} \text { Standard Deviation } \\
\star{ }^{\star \star} \text { Interquartile Range } \\
\star \star \star \star A\end{array}$ & & & & & & \\
\hline
\end{tabular}

We did not evaluate cost-effectiveness because this would require decades of follow-up. When we searched PubMed using the key words "cost, hepatitis B" and "cost, hepatitis C" we could not find any studies of real patients that included decades of follow up. Among the advantages of our study was that we included all patients with chronic hepatitis B and $C$ followed up by our clinic and hospitalised during the study period and that we evaluated treatment, hospital and indirect costs for real patients. We therefore evaluated actual treatment costs by using real drug doses. In contrast, studies based on models did not evaluate indirect costs.

One study (2) found that most of the total costs consisted of indirect costs, with most of the latter consisting of loss of work. Loss of efficiency was highest in patients with acute and chronic hepatitis $B$ and the premature death rates were higher in patients with cirrhosis and/or HCC.

In our study, most of the total costs consisted of treatment costs. The drugs had to be obtained from abroad at high costs. Workers generally came to the hospital between shifts to prevent the loss of work, and most of these patients used free transportation, thus minimising indirect costs as a fraction of total costs.

We found that indirect costs to primary school graduates were the highest. Most of these individuals were farmers who had to come from rural areas. Thus, their higher indirect costs were due to the costs of transportation.

We found that total costs were 10-fold higher in patients with than without cirrhosis, with most of these costs being due to hospital costs. A previous study showed that the direct costs of patients with cirrhosis were 3-fold higher than those of patients with chronic hepatitis $B$, as were indirect costs (2). Although hospital costs were 10-fold higher in patients with compensated cirrhosis than those with chronic hepatitis $B$, their antiviral treatment costs were similar (13). We found that the frequencies of invasive examinations and hospitalisation were higher in patients with than without cirrhosis, but that the treatment costs of these two groups did not differ significantly because all of our patients with cirrhosis had compensated cirrhosis, with similar treatments for these two groups.

A cost comparison in inactive HBV carriers without any treatment, HBV patients who took lamivudine monotherapy for one year and HBV patients who took lamivudine-adefovir therapy for five years found that, when the costs of the treatments were evaluated together with their ability to stop disease progression, the lamivudine-adefovir combination was optimal (14). In Turkey, the Social Security Foundation does not pay the costs of combination therapy for chronic hepatitis 
B so none of our chronic hepatitis B patients took combination therapy. Moreover, the previous study did not include the costs of the new generation of antiviral agents, such as tenofovir and entecavir.

Comparisons of lamivudine and pegylated interferon-alpha 2a therapy for 1 year in patients with chronic hepatitis $B$ showed that peg-interferon alpha-2a was more cost-effective, but all of those patients were naive to treatment and at the same disease stage $(15,16)$. We found that the costs of pegylated interferon alpha-2a and $-2 b$ were higher than those of lamivudine, but hospital costs did not differ significantly. Our study was more encompassing, in that it included patients not naive to treatment and at different disease stages.

A comparison of lamivudine with peg-interferon followed by lamivudine showed that the mean costs of the former were 14,100 United States Dollars (USD) higher. In contrast, we found that previous antiviral treatment did not significantly affect overall costs.

A comparison of tenofovir, entecavir, telbivudine and adefovir in patients with chronic hepatitis B showed that tenofovir was more cost-effective than the other agents (17). Similarly, we found that the treatment and total costs of tenofovir were less than those of entecavir and adefovir.

As no previous studies have assessed the costs of chronic hepatitis $C$ based on real patients, we compared our findings with those of studies using Markov models.

Asymptomatic chronic hepatitis $C$ was found to significantly reduce productivity and ability to work and was associated with high healthcare costs (18). Mean annual income was 8352 USD lower in individuals with than without HCV. We found that the indirect, hospital, treatment and total costs of chronic hepatitis $C$ patients were less than those of chronic hepatitis $B$ patients, but higher than those of inactive HBV carriers. While $50 \%$ of our chronic HCV patients achieved viral response, they were seen at our hospital at 6-12 month intervals for the evaluation of $\mathrm{HCC}$ and/or relapse, reducing their ability to work and increasing treatment costs.

The combination of pegylated interferon-alpha and ribavirin was found to be more cost-effective than pegylated interferon-alpha alone in patients with chronic hepatitis $C$ (19). This model assumed that a sustained viral response would occur and that survival would be the same as in individuals without chronic hepatitis $C$. In practice, however, some patients with sustained viral response relapse, whereas some refractory to treatment progress to cirrhosis.

A model of chronic hepatitis $C$ patients at age 40 years with high ALT levels found that the cost-benefits of treatment would be greater in women than in men, primarily because the probability of progressing to cirrhosis is lower in women (20). That model, however, did not evaluate relapsed patients and those refractory to treatment. We found that $75 \%$ of $\mathrm{HCV}$ patients with cirrhosis were males, whereas $66.7 \%$ of those who relapsed were females. Comorbid factors should therefore be considered when evaluating the effectiveness of treatment.

This study had several limitations. First, it was hospitalbased; therefore, the results cannot be generalised to all patients with viral hepatitis. In addition, none of our patients had undergone liver transplantation or had liver cancer, preventing the evaluation of costs at all stages of chronic hepatitis $B$ and $C$.

In conclusion, chronic hepatitis $B$ and $C$ remain important healthcare problems, with costs increasing with stage of liver disease. Treatment costs constituted the largest fraction of total costs. The treatment and total costs of adefovir therapy were higher than those of lamivudine, tenofovir or entecavir therapy. The direct and indirect costs of these diseases on the Turkish economy suggest the need for greater prevention.

Ethics Committee Approval: This study was approved by the Ethics Committee of Pamukkale University Faculty of Medicine (date: 29.06.2009, decision number: 09)

Informed Consent: Written informed consent was obtained from the participants of this study.

Peer-review: Externally peer-reviewed.

Author contributions: Concept - F.B.K., S.S.; Design - F.B.K., A.A., S.S.; Supervision - S.S., H.T.; Resource - F.B.K., S.S.; Materials - F.B.K., S.S.; Data Collection\&/or Processing - F.B.K.; Analysis\&/or Interpretation F.B.K., S.S.; Literature Search - F.B.K.; Writing - F.B.K., A.A., S.S.; Critical Reviews - S.S., H.T.

Acknowledgements: The authors would like to thank Prof. Hüseyin Turgut, Assoc. Prof. Suzan Saçar and Prof. Mehmet Zencir for their support and contributions during the preparation of the manuscript.

Conflict of Interest: The authors declared no conflict of interest.

Financial Disclosure: The authors declared no financial disclosure.

\section{References}

1. Chen CJ, Yang HI, Su J, et al. Serial monitoring of viral load and serum alanine aminotransferase level and the risk of hepatocellular carcinoma (HCC): R.E.V.E.A.L.- HBV study update. In: 43rd Annual Meeting of the European Association for the Study of the Liver (EASL 2008); 2008 April 23- 27; Milan, Italy.

2. Yang BM, Paik SW, Hahn OS, Yi DH, Choi MS, Payne S. Economic evaluation of the societal costs of hepatitis B in South Korea. J Gastroenterol Hepatol 2001;16:301-8. [CrossRef]

3. Kim WR, Poterucha JJ, Hermans JE, Therneau TM, Dickson ER, Evans RW, et al. Cost-effectiveness of 6 and 12 months of interferon-alpha therapy for chronic hepatitis C. Ann Intern Med 1997; 127:866-74. [CrossRef]

4. Lok ASF, McMahon BJ. Chronic hepatitis B: update 2009. Hepatology 2009;50:661-2. [CrossRef]

5. European Association for the Study of the Liver. EASL Clinical Practice Guidelines: management of chronic hepatitis B. J Hepatol 2009;50:227-42. [CrossRef]

6. Piratvisuth T. Reviews for APASL guidelines: Immunomodulator therapy of chronic hepatitis B. Hepatol Int 2008;2:140-6. [CrossRef]

7. Lok AS, McMahon BJ; Practice Guidelines Committee, American Association for the Study of Liver Diseases (AASLD). Chronic hepatitis B: update of recommendations. Hepatology 2004;39:857-61. [CrossRef]

8. McMahon BJ. Epidemiology and natural history of hepatitis B. Semin Liver Dis 2005;25 Suppl 1: 3-8. [CrossRef]

9. Lavanchy D. Hepatitis B virus epidemiology, diseases burden, treatment, and current and emerging prevention and control measures. J Viral Hepat 2004;11:97-107. [CrossRef]

10. Gold MR, Siegel JE, Russell LB, Weinstein MC. Cost-effectiveness in health and medicine. New York: Oxford University Pres 1996.

11. Wong JB. Hepatitis C: cost of illness and considerations for the economic evaluation of antiviral therapies. Pharmacoeconomics 2006;24:661-72. [CrossRef] 
12. Faissol DM, Griffin PM, Swann JL. Bias in Markov models of diseases. Math Biosci 2009;220:143-56. [CrossRef]

13. Li SC, Ong SC, Lim SG, Yeoh KG, Kwong KS, Lee V, et al. A cost comparison of management of chronic hepatitis $B$ and its associated complications in Hong Kong and Singapore. J Clin Gastroenterol 2004;38:S136-43. [CrossRef]

14. Lacey LF, Gane E. The cost-effectiveness of long-term antiviral therapy in the management of $\mathrm{HBeAg}$-positive and $\mathrm{HBeAg}$-negative chronic hepatitis B in Singapore. J Viral Hepat 2007;14:751-66. [CrossRef]

15. Sullivan SD, Veenstra DL, Chen PJ, Chang TT, Chuang WL, Tsai $C$, et al. Cost- effectiveness of peginterferon alpha-2a compared to lamivudine treatment patients with hepatitis $B$ e antigen positive chronic hepatitis B in Taiwan. J Gastroenterol Hepatol 2007;22:1494-9. [CrossRef]
16. Vanagas G, Padaiga Z, Mickeviciene A. Cost-effectiveness and cost-utility of the treatment of chronic hepatitis $B$ with peginterferon alfa-2a, interferon alfa, and lamivudine in Lithuania. Medicana (Kaunas) 2010;46:835-42.

17. Buti M, Brosa M, Casado MA, Rueda M, Esteban R. Modeling the cost-effectiveness of different oral antiviral therapies in patients with chronic hepatitis B. J Hepatol 2009;51:640-6. [CrossRef]

18. Su J, Brook RA, Kleinman NL, Corey-Lisle P. The impact of hepatitis $C$ virus infection on work absence, productivity, and healthcare benefit costs. Hepatology 2010;52:436-42 [CrossRef]

19. Stein K, Rosenberg W, Wong J. Cost effectiveness of combination therapy for hepatitis C: a decision analytic model. Gut 2002;50:253-8. [CrossRef]

20. Salomon JA, Weinstein MC, Hammitt JK, Goldie SJ. Cost-effectiveness of treatment for chronic hepatitis $\mathrm{C}$ infection in an evolving patient population. JAMA 2003;290:228-37. [CrossRef] 